\title{
Isolation and characterization of the major oligosaccharide of human platelet membrane glycoprotein GPIb
}

\author{
Philip A. JUDSON,* David J. ANSTEE* and John R. CLAMP $\dagger$ \\ *Department of Immunochemistry, South Western Regional Blood Transfusion Centre, Southmead, Bristol \\ BS10 5ND, U.K., and †Department of Medicine, Bristol Royal Infirmary, Bristol BS2 8HW, U.K.
}

\section{(Received 15 January 1982/Accepted 5 April 1982)}

\begin{abstract}
Treatment of intact human platelets with chymotrypsin released a glycopolypeptide that was shown to be derived from the major membrane glycoprotein, GPIb. The glycopolypeptide contained $59 \%$ carbohydrate on a molar basis and was rich in serine, threonine and proline. Almost all the carbohydrate could be released from the glycopolypeptide by treatment with alkali in the presence of $\mathrm{NaBH}_{4}$. The major component (comprising $80 \%$ of the released sugar) was purified and shown to be a hexasaccharide containing sialic acid, galactose, $\mathrm{N}$-acetylglucosamine and $\mathrm{N}$-acetylgalactosaminitol in the molar ratios $2: 2: 1: 1$. Two possible structures for this hexasaccharide are proposed on the basis of the known biosynthetic pathways of mucus-type glycoproteins. Our data is consistent with the occurrence of an $O$ glycosidically linked oligosaccharide on one amino acid in four of the glycopolypeptide. These results suggest that glycoprotein $\mathrm{Ib}$ can best be described as a membrane-bound mucus-type glycoproteins. Our data are consistent with the occurrence of an $O$ in the process by which platelets adhere to the exposed subendothelium of damaged blood-vessel walls. The possible role of the glycopolypeptide portion of GPIb in this process was investigated. Neither the major oligosaccharide nor the glycopolypeptide itself inhibited ristocetin-induced platelet agglutination at the concentrations tested. It is suggested that the carbohydrate moieties of GPIb molecules at the cell surface interact to form a barrier to macromolecules. Such a barrier could play a major role in modulating platelet function.
\end{abstract}

Platelets play an essential role in haemostasis, their functions being controlled by the interaction of effector molecules with receptors on the platelet membrane. Specific glycoproteins are thought to be required as receptors during adhesion to subendothelium and also platelet aggregation, both important steps in the haemostatic response to vessel injury (Phillips, 1980).

A major platelet membrane glycoprotein, GPIb, has an apparent $M_{\mathrm{r}}$ of 170000 , consists of two disulphide-linked subunits [GPIb $\alpha(143000 \mathrm{Da})$ and GPIb $\beta$ (22000 Da) (Phillips \& Poh Agin, 1977)] and is thought to be functionally important in platelet adhesion to subendothelium (Nurden \& Caen, 1978). Pepper \& Jamieson (1970) showed that treatment of intact platelets with proteinases could release a 'macroglycopeptide' thought to be derived from GPIba (in the present nomenclature). Sub-

Abbreviations used: GPIb, glycoprotein Ib; SDS, sodium dodecyl sulphate; SA (in sequences), sialic acid (probably, but not certainly, $\mathrm{N}$-acetylneuraminate). sequently Okumura et al. (1976) showed that this 'macroglycopeptide' is a proteolytic fragment of a larger glycoprotein, glycocalicin, which itself is likely to be a fragment of GPIba (Solum et al., 1980; Clemetson et al., 1981). GPIb appears to be the major sialoglycoprotein of the platelet membrane, since, when glycocalicin is solubilized from platelets by freeze-thawing (in the absence of proteinase inhibitors and EDTA), $64 \%$ of the total acid-labile sialic acid of intact platelets is released (Solum et al., 1980).

We report here the isolation and partial characterization of the major oligosaccharide present on glycoprotein Ib and investigate its possible role in one of the (non-physiological) receptor functions of GPIb, ristocetin-induced platelet agglutination.

\section{Materials and general methods}

Outdated human platelet concentrates were available from the South Western Regional Blood Transfusion Centre, Bristol, U.K. $\alpha$-Chymotrypsin 
(type II) was from Sigma (London) Chemical Co. Ltd., Poole, Dorset, U.K. Neuraminidase (from Vibrio cholerae) was from Behringwerke AG, Marburg, Germany, and purified wheat-germ agglutinin (from Triticum vulgaris), Phaseolus vulgaris (red kidney bean) agglutinin and concanavalin $\mathrm{A}$ [from jack bean (Canavalia ensiformis)] were purchased from Calbiochem (London, U.K.), Difco (Detroit, MI, U.S.A.) and Pharmacia (London, U.K.) respectively and were used without further purification. The lectins from castor bean (Ricinus communis) (Thompson and Morgan Ltd., Ipswich, Suffolk, U.K.), osage orange [Maclura aurantiaca (pomifera)] (Schumacher Ltd., Sandwich, MA, U.S.A.) and Arachis hypogaea (peanut) were purified from crude seed extracts by absorption to, and elution from, formaldehyde-treated erythrocytes (Tanner \& Anstee, 1976).

Haemagglutination-inhibition tests using lectins were performed in $7 \mathrm{~mm} \times 50 \mathrm{~mm}$ tubes, using standard serological techniques with human group$\mathrm{O}$ erythrocytes. Neuraminidase-treated erythrocytes were used as indicator cells for experiments involving Arachis hypogaea lectin and trypsintreated erythrocytes for those involving wheat-germ agglutinin, concanavalin $\mathrm{A}$ and Phaseolus vulgaris lectins. The methods of neuraminidase treatment and trypsin treatment of erythrocytes are described elsewhere (Anstee et al., 1979; Tanner et al., 1980).

SDS/polyacrylamide-gel electrophoresis was in slab gels containing $7 \%(\mathrm{w} / \mathrm{v})$ acrylamide and with a $3 \%$ overlay, the discontinuous buffer system of Laemmli (1970) being used. Samples for SDS/ polyacrylamide-gel electrophoresis were solubilized by the addition of an equal volume of $10 \%$ SDS and boiled for $2 \mathrm{~min}$. A sample was removed for protein determination (Lowry et al., 1951). To the remainder, $\frac{1}{2}$ vol. of sample buffer was added and the sample was boiled again for $2 \mathrm{~min}$. Reduced samples were made $5 \%$ with respect to 2 -mercaptoethanol, before boiling with sample buffer. Gels were stained with periodic acid/Schiff's-base stain (Zacharias et al., 1969). Chymotrypsin was assayed by the method of Hummel (1959), with benzoyl-L-tyrosine ethyl ester (Sigma) as substrate. Samples for amino acid analysis were hydrolysed in constant-boiling $\mathrm{HCl}$ under $\mathrm{N}_{2}$ at $110^{\circ} \mathrm{C}$ for 24,72 and $96 \mathrm{~h}$ before determination on a Rank-Hilger Chromaspek amino acid analyser. Values for serine and threonine were extrapolated to zero time to overcome losses occurring during hydrolysis, and values for isoleucine, leucine and valine taken after complete hydrolysis for $96 \mathrm{~h}$. $O$-Linked oligosaccharides were released from the chymotryptic glycopolypeptide $(1-2 \mathrm{mg} / \mathrm{ml})$ by treatment with $1 \mathrm{M}-\mathrm{NaBH}_{4} / 0.05 \mathrm{M}-$ $\mathrm{NaOH}$ for $20 \mathrm{~h}$ at $50^{\circ} \mathrm{C}$ in the dark (Farrar \& Harrison, 1978). The solution was then cooled in ice, neutralized by the addition of Dowex 50WX8 resin (acid-washed, $\mathrm{H}^{+}$form; $\mathrm{BDH}$ ) until effervescence ceased, and freeze-dried. The residue was freed of boric acid by repeated addition of methanol and removal by evaporation under reduced pressure and dissolved in $50 \mathrm{~mm}$-acetic acid. Sialic acid was measured by the resorcinol (Svennerholm, 1957) or the thiobarbituric acid method (Aminoff, 1961). Total hexose was assayed by the method of Dische \& Danilchenko (1967). G.l.c. of monosaccharides was carried out by the procedure described by Clamp (1977).

T.l.c. on plates of silica-gel $\mathrm{G}$ (BDH) was performed with two solvent systems: butanol/propanol/water $(3: 5: 2$, by vol.) and butanol/acetic acid/water $(75: 25: 6$, by vol.). Samples and standards $(1 \mathrm{mg} / \mathrm{ml})$ in water were applied in a volume of 5-15 $\mu$, and, after chromatography, the spots were made visible with the orcinol spray reagent (Humbel \& Collart, 1975). Some samples were desialylated by adding $0.1 \mathrm{M}-\mathrm{H}_{2} \mathrm{SO}_{4}(50 \mu \mathrm{l})$ to the sample $(0.3 \mathrm{mg} /$ $\mathrm{ml} ; 50 \mu \mathrm{l})$ and heating for $1 \mathrm{~h}$ in a sealed tube. The solutions were cooled and were neutralized with $0.1 \mathrm{M}-\mathrm{NaOH}(50 \mu \mathrm{l})$.

Ristocetin-induced platelet agglutination was carried out with platelet-rich plasma prepared from fresh blood by differential centrifugation (Taylor, 1981). The platelet-rich plasma was adjusted to contain $2 \times 10^{8}$ platelets $/ \mathrm{ml}$ with autologous plasma, and $1 \mathrm{ml}$ was placed in the cuvette of a Bryston aggregometer (Albert Browne Ltd., Leicester, U.K.) and maintained at $37^{\circ} \mathrm{C}$ with constant stirring. Inhibition of ristocetin-induced agglutination was studied by adding inhibitor diluted in $0.15 \mathrm{M}-\mathrm{NaCl}$ $(100 \mu \mathrm{l})$, followed $1 \mathrm{~min}$ later by 80 or $100 \mu \mathrm{l}$ of ristocetin solution $(16 \mathrm{mg} / \mathrm{ml}$ in $0.15 \mathrm{M}-\mathrm{NaCl})$. Change in light transmission was recorded over a 5-min period. Ristocetin was from Lundbeck, Copenhagen, Denmark, and glycocalicin (Okumura \& Jamieson, 1976a) was prepared by the method of Solum et al. (1980), the affinity-chromatography step being omitted.

\section{Results}

Platelets were obtained from outdated human platelet concentrates by differential centrifugation at room temperature in $150 \mathrm{~mm}-\mathrm{NaCl} / 50 \mathrm{~mm}$-sodium phosphate buffer, pH6.5, containing $1 \mathrm{~mm}$-EDTA (Barber \& Jamieson, 1970). The washed platelets (purity >95\%) $\left(2 \times 10^{9} / \mathrm{ml}\right)$ were suspended in $150 \mathrm{~mm}-\mathrm{NaCl} / 50 \mathrm{~mm}$-sodium phosphate, $\mathrm{pH} 8.0$, containing $1 \mathrm{mg}$ of $\alpha$-chymotrypsin $/ \mathrm{ml}$, for $1.5 \mathrm{~h}$ at $37^{\circ} \mathrm{C}$. The treated platelets were removed by centrifugation $(6000 \mathrm{~g} / 15 \mathrm{~min})$ and analysed by SDS/polyacrylamide-gel electrophoresis (Fig. 1). The results clearly showed a gross reduction of periodate-Schiff staining in the region of GPIba. A concomitant reduction in the staining intensity of 
GPIIb $\alpha$ was also apparent. The other major periodate-Schiff-staining bands appeared unaffected by the treatment.

The clear supernatant obtained after chymotrypsin treatment of the platelet suspension (crude

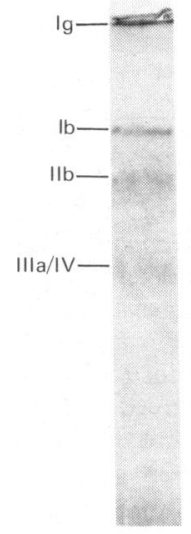

(a)

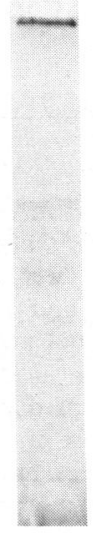

(b)

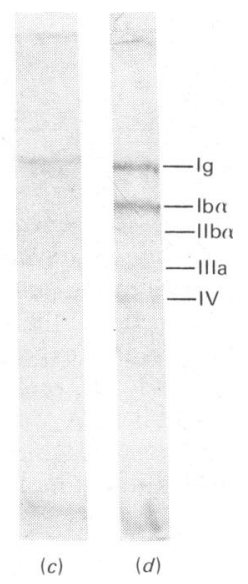

Fig. 1. SDS/polyacrylamide-gel electrophoresis of normal and chymotrypsin-treated human platelets

Electrophoresis was in a slab containing $7 \%(w / v)$ acrylamide with an overlay of $3 \%$ acrylamide as described in the Materials and general methods section. (a) Normal platelets under non-reducing conditions; $(b)$ chymotrypsin-treated platelets under non-reducing conditions; $(c)$ chymotrypsin-treated platelets under reducing conditions; (d) normal platelets under reducing conditions. The gel was stained with periodate/Schiff reagent. glycopolypeptide) was concentrated 10 -fold by ultrafiltration (Amicon PM10 membrane) and subjected to gel-permeation chromatography on a column of Sephadex G-200. The elution profile obtained (Fig. 2) was essentially the same as that reported by Barber \& Jamieson (1971). The major sialic acid-rich peak (Peak I) was eluted just after the material at the void volume of the column. The fractions comprising this sialic acid-rich peak (glycopolypeptide) were pooled and concentrated by ultrafiltration (Amicon PM10 membrane). About $9 \mathrm{mg}$ of Peak I material (purified glycopolypeptide) was obtained from $2 \times 10^{11}$ platelets.

Analysis of the glycopolypeptide by haemagglutination inhibition using selected lectins (Table 1) established that this glycopolypeptide is derived from GPIba, since Arachis hypogaea (peanut) lectin, which binds exclusively to GPIb $\alpha$ in desialylated platelet membranes (Judson \& Anstee, 1979; Clemetson et al., 1981), is inhibited by desialylated glycopolypeptide. The amino acid and carbohydrate composition of the glycopolypeptide is given in Table 2. The glycopolypeptide contains $59 \mathrm{~mol} \%$ of carbohydrate, the predominant sugars being galactose, $\mathrm{N}$-acetylglucosamine, $\mathrm{N}$-acetylgalactosamine and sialic acid. It is rich in serine, threonine and proline, but lacks cysteine. $O$-Glycosidically linked oligosaccharides were isolated by treatment with an alkaline solution of $\mathrm{NaBH}_{4}$, followed by gel-permeation chromatography (Fig. 3). Assay of the eluted material for hexose and sialic acid revealed three peaks, and the relevant fractions were pooled as indicated (Fig. 3 and Table 3). The major carbohydrate-containing peak (I-3) was further purified by

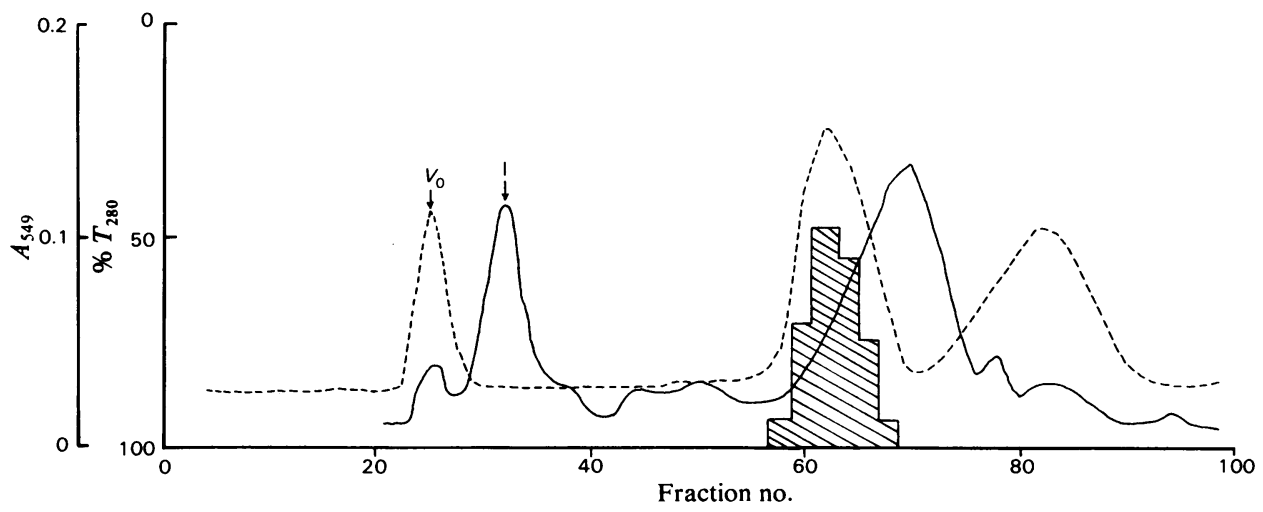

Fig. 2. Gel-permeation chromatography of peptides released by chymotrypsin digestion of intact platelets Concentrated supernatant $(10 \mathrm{ml})$ obtained after $\alpha$-chymotrypsin treatment of intact platelets was applied to a column of Sephadex G-200 $(86 \mathrm{~cm} \times 2.5 \mathrm{~cm})$ and eluted at a flow rate of $9 \mathrm{ml} / \mathrm{h}$. Fractions $(5 \mathrm{ml})$ were collected. Percentage transmission at $280 \mathrm{~nm}\left(\% T_{280}\right)$ of the effluent was measured continuously $(----)$ and fractions were assayed for sialic acid (-) and chymotrypsin activity $(\mathbb{N})$ as described in the Materials and general methods section. Fractions 30-35 were pooled and denoted 'Peak I'. $V_{0}$ indicates the void volume of the column. 
Table 1. Lectin-binding properties of platelet glycopolypeptide

The ability of glycopolypeptide (Peak I material prepared as in Fig. 2) to inhibit lectin-mediated agglutination was determined as described in the Materials and general methods section. The numbers indicate the minimum quantity of glycopolypeptide ( $\mu \mathrm{g}$; based on hexose assay) necessary to inhibit three haemagglutinating doses of lectin.

\begin{tabular}{|c|c|c|c|c|c|c|c|}
\hline \multirow[t]{2}{*}{ Lectin } & $\ldots$ & $\begin{array}{l}\text { Wheat-germ } \\
\text { agglutinin }\end{array}$ & $\begin{array}{l}\text { Phaseolus } \\
\text { vulgaris }\end{array}$ & $\begin{array}{c}\text { Concanavalin } \\
\text { A }\end{array}$ & $\begin{array}{l}\text { Ricinus } \\
\text { communis }\end{array}$ & $\begin{array}{c}\text { Maclura } \\
\text { aurantiaca }\end{array}$ & $\begin{array}{c}\text { Arachis } \\
\text { hypogaea }\end{array}$ \\
\hline & & 24 & 6 & $>24$ & 12 & 6 & $>24 \quad 8^{*}$ \\
\hline
\end{tabular}

* Desialylated glycopolypeptide.

Table 2. Composition of glycopolypeptide Amino acid and carbohydrate analysis was carried out as described in the Materials and general methods section. The material contained glucose but since Sephadex was used in the purification procedure (Fig. 2), the value obtained was considered unreliable and was not used for the calculation of the molar ratios.

$\begin{array}{lc}\text { Aspartic acid } & \begin{array}{c}\text { Content } \\ \text { (mol \%) }\end{array} \\ \text { Threonine } & 1.29 \\ \text { Serine } & 7.15 \\ \text { Glutamic acid } & 4.55 \\ \text { Proline } & 3.17 \\ \text { Glycine } & 6.08 \\ \text { Alanine } & 0.99 \\ \text { Valine } & 1.4 \\ \text { Cysteine } & 1.3 \\ \text { Methionine } & - \\ \text { Isoleucine } & 0.13 \\ \text { Leucine } & 1.38 \\ \text { Tyrosine } & 2.7 \\ \text { Phenylalanine } & 1.81 \\ \text { Lysine } & 2.9 \\ \text { Histidine } & 1.4 \\ \text { Arginine } & 2.9 \\ \text { Mannose } & 1.12 \\ \text { Galactose } & 4.2 \\ \text { Glucose } & 17.8 \\ N \text {-Acetylglucosamine } & 10.8 \\ N \text {-Acetylgalactosamine } & 10.9 \\ \text { Sialic acid } & 14.9 \\ \text { Fucose } & 0.3\end{array}$

ion-exchange chromatography on DEAE-Sephadex A-25 (Farrar \& Harrison, 1978). Two sialic acidcontaining peaks were resolved (Fig. 4). The major peak (I-3A) accounted for more than $80 \%$ of the material released by $\beta$-elimination of the glycopolypeptide and had the carbohydrate composition shown in Table 3. Insufficient material corresponding to peak I-3B was obtained for analysis. Peak I-3A contained $\mathrm{N}$-acetylgalactosaminitol, $\mathrm{N}$ -
Table 3. Carbohydrate composition of products of alkaline-borohydride digest of the glycopolypeptide Carbohydrate compositions were determined as described in the Materials and general methods section and expressed as $\mathrm{nmol} / \mathrm{mg}$. Fractions I-1, I-2, and I-3 were prepared as described in Fig. 3. Fraction I-3A was prepared as described in Fig. 4. The value obtained for glucose was not used in the calculation of molar ratios (See Table 2).

\begin{tabular}{|c|c|c|c|c|}
\hline \multirow[b]{2}{*}{ Fraction no. } & \multicolumn{4}{|c|}{ Composition $(\mathrm{nmol} / \mathrm{mg})$} \\
\hline & I-1 & $\mathrm{I}-2$ & $\mathrm{I}-3$ & I-3A \\
\hline Fucose & - & 17 & - & - \\
\hline Mannose & - & 37 & - & - \\
\hline Galactose & 15 & 84 & 526 & 157 \\
\hline Glucose & 515 & 15 & 30 & - \\
\hline Glucuronic acid & 79 & - & - & - \\
\hline$N$-Acetylglucosamine & 6 & 50 & 221 & 67 \\
\hline$N$-Acetylgalactosamine & 44 & 26 & 34 & - \\
\hline Sialic acid & - & 100 & 652 & 168 \\
\hline $\mathrm{N}$-Acetylgalactosaminitol & - & - & 254 & 75 \\
\hline
\end{tabular}

acetylglucosamine, galactose and sialic acid in the molar ratios $1.0: 0.9: 2.1: 2.2$ respectively.

The material in Peak I-3A gave a single symmetrical peak when subjected to gel-permeation chromatography on a column of Sephadex G-25 $(145 \mathrm{~cm} \times 13 \mathrm{~cm})$ and appeared homogeneous both before and after desialylation when examined by t.l.c. with the butanol/acetic acid/water solvent mixture. With butanol/propanol/water (Fig. 5) Peak I-3A material gave a major spot with $R_{F} 0.09$ and a faint spot with $R_{F} 0.20$. When desialylated, Peak I-3A material migrated as a major spot with $R_{F} 0.20$, and a very faint spot with $R_{F} 0.45$. Estimation of the apparent molecular weights of Peak I-3A and desialylated Peak I-3A material on a calibrated column of Sephadex G-25 (Fig. 6) gave values of 1400 and 900 respectively.

Experiments to determine the involvement of GFIb in ristocetin-induced platelet agglutination showed that neither the major oligosaccharide I-3A nor the glycopolypeptide had a significant inhibitory 


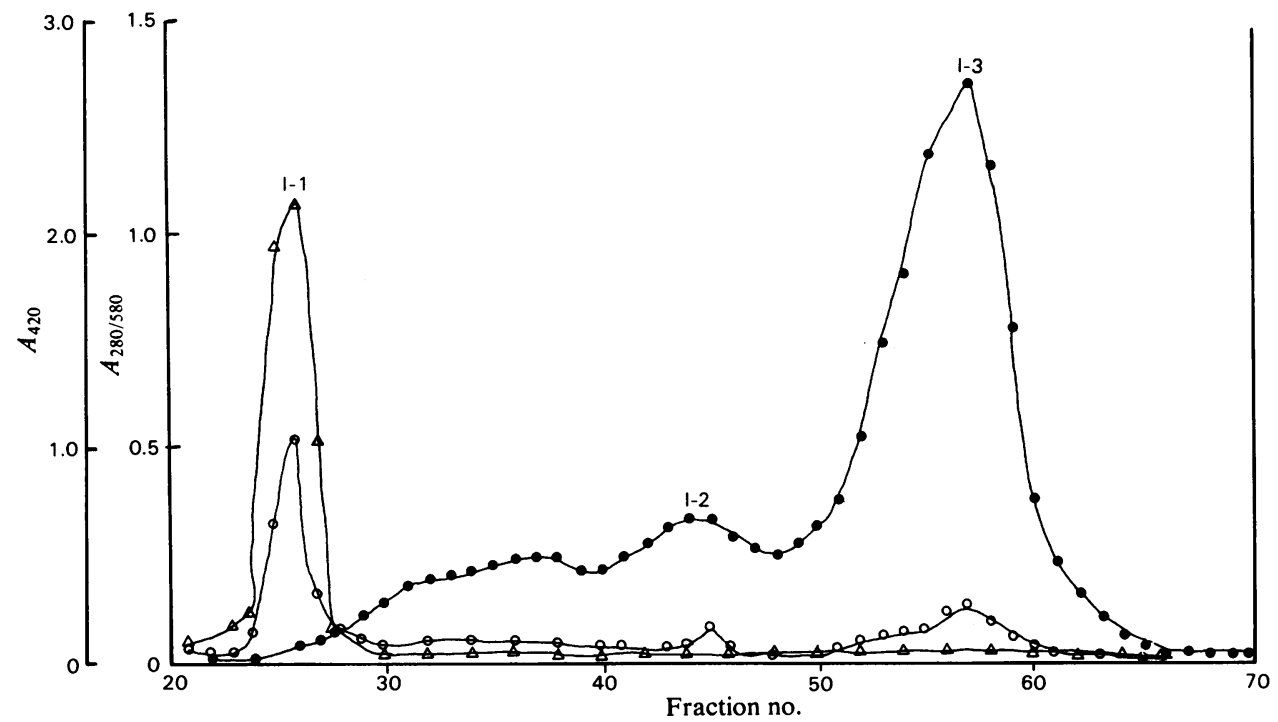

Fig. 3. Gel-permeation chromatography of alkaline-borohydride digest of platelet glycopolypeptide The products from alkaline-borohydride treatment of the glycopolypeptide $(5 \mathrm{mg})$ were separated on a column $(115 \mathrm{~cm} \times 1.5 \mathrm{~cm})$ of Sephadex G-50 and eluted at a flow rate of $20 \mathrm{ml} / \mathrm{h}$ with $50 \mathrm{~mm}$-acetic acid. Fractions $(3 \mathrm{ml})$ were collected. The $A_{280}$ of the effluent was measured continuously $(\Delta)$ and fractions were assayed for sialic acid ( $(\bullet)$ and hexose (O). Fractions 24-27, 41-47 and 51-61 were pooled and termed 'I-1', 'I-2' and 'I-3' respectively.

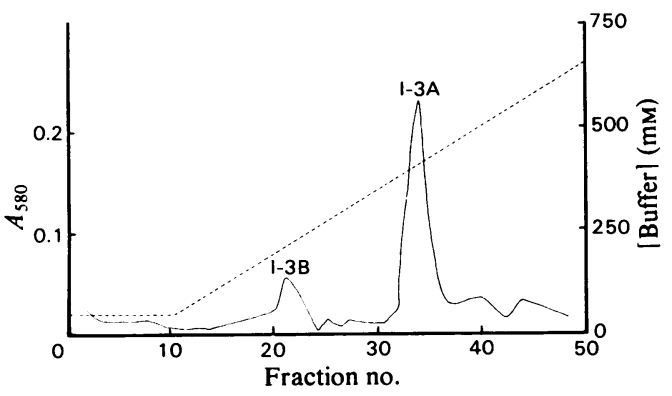

Fig. 4. Ion-exchange chromatography of fraction I-3 Fraction I-3 (85 $\mu \mathrm{g}$ of hexose) was prepared as in Fig. 3 and applied to a column $(25 \mathrm{~cm} \times 1.5 \mathrm{~cm})$ of Sephadex A-25 equilibrated with $50 \mathrm{~mm}$-pyridine/ acetate buffer, $\mathrm{pH}$ 5.0. The column was washed with a further $50 \mathrm{ml}$ of equilibrating buffer after sample addition, before application of a linear gradient of 50-650 mM-pyridine/acetate buffer, pH $5.0(200 \mathrm{ml})$. Fractions $(5 \mathrm{ml})$ were collected at a flow rate of $40 \mathrm{ml} / \mathrm{h}$. A portion of each fraction was freeze-dried, reconstituted in distilled water $(0.1 \mathrm{ml})$ and assayed for sialic acid. - $\longrightarrow$, Sialic acid; ----, buffer gradient. Fractions 21-23 (I-3B) and Fractions 32-36 (I-3A) were pooled and freeze-dried.

effect (Figs. $7 a$ and $7 b$ ) at the concentrations tested. However, glycocalicin at $0.2 \mathrm{mg} / \mathrm{ml}$ reduced the extent of agglutination to about $25 \%$ of that of the control (Fig. 7c).

\section{Discussion}

Treatment of intact platelets with chymotrypsin results in the solubilization of a number of membrane-derived peptides without the concomitant initiation of the platelet-release reaction (Barber \& Jamieson, 1971; Davey \& Lüscher, 1967). Although a number of membrane proteins may be affected (Podolsak, 1977), the major soluble product originates from GPIb and is a glycopolypeptide of high molecular weight that can be readily purified by gel-permeation chromatography on Sephadex G-200. Similar material was designated 'macroglycopeptide' by Pepper \& Jamieson (1970). This term indicates high-molecular-weight carbohydrate units (polysaccharide) attached to peptide. Our results, however, show that the material consists of large numbers of oligosaccharide units attached to a polypeptide. The preferred term therefore is 'glycopolypeptide' (Reid \& Clamp, 1978) and is the term used throughout the present paper.

Features of interest in the glycopolypeptide are a high content of serine, threonine and proline, low levels of asparagine, hydrophobic amino acids and an absence of cysteine. The glycopolypeptide is heavily glycosylated, consisting of $59 \%$ carbohydrate on a molar basis. A glycopolypeptide isolated from combined tryptic and Pronase digests of intact platelets (Pepper \& Jamieson, 1970) had very similar amino acid and carbohydrate com- 


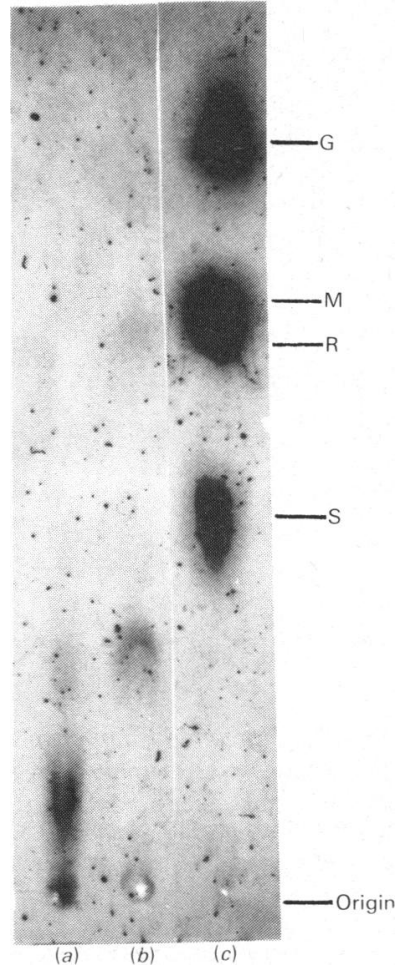

Fig. 5. T.l.c. analysis of I-3A

I-3A and desialylated I-3A was analysed by t.l.c. as described in the Materials and general methods section. Butanol/propanol/water was the solvent. (a) I-3A; (b) desialylated I-3A; (c) standards: glucose $(G)$, melibiose (M), raffinose (R) and stachyose (S).

positions to those reported here (correlation coefficient, $r=0.94$ ).

Our data indicate that most of the carbohydrate is $\mathrm{O}$-glycosidically linked through $\mathrm{N}$-acetylgalactosamine to serine or threonine, which together comprise about $25 \%$ of the total amino acids of the glycopolypeptide. Assuming a single $N$-acetylgalactosamine residue per oligosaccharide, this indicates that, on average, every fourth amino acid in the glycopolypeptide is glycosylated (approx. 60 oligosaccharide chains per molecule). The high level of substitution with $O$-linked oligosaccharides and the overall amino acid composition of the glycopolypeptide is similar to the glycosylated, Pronaseresistant regions of blood-group substances and mucus glycoproteins (Donald, 1973; Goodwin \& Watkins, 1974). Furthermore, both GPIb and mucus glycoproteins consist of disulphide-linked subunits (Phillips \& Poh Agin, 1977; Allen, 1978), which are comprised of glycosylated and nonglycosylated regions (Okumura et al., 1976; Allen, 1978).

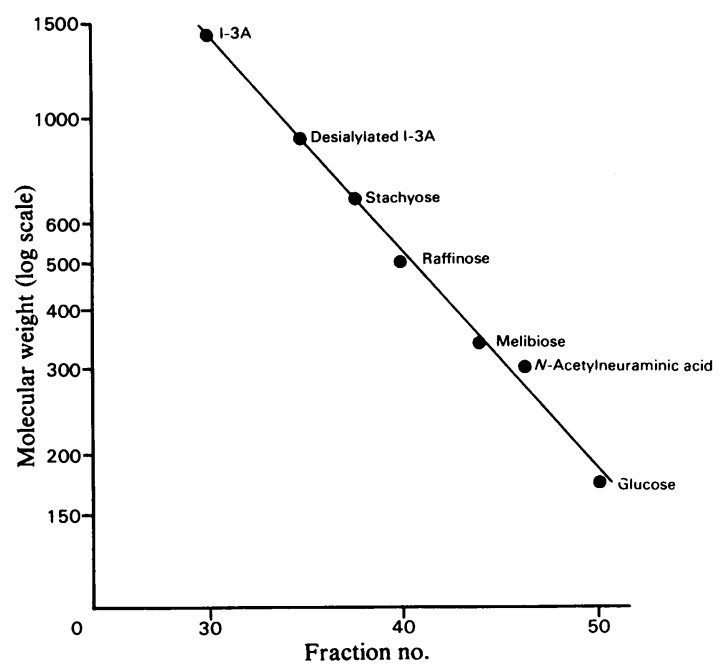

Fig. 6. Molecular-weight determinations of I-3A I-3A, desialylated I-3A and standard reference sugars were applied separately to a column $(145 \mathrm{~cm} \times 1.3 \mathrm{~cm})$ of Sephadex G-25 equilibrated in $50 \mathrm{~mm}$-acetic acid, at a flow rate of $20 \mathrm{ml} / \mathrm{h}$. Their elution volumes (expressed as fraction numbers) were measured and plotted against molecular weight (expressed on a logarithmic scale).

The major $O$-glycosidically linked oligosaccharide fraction (I-3A) of the glycopolypeptide was isolated, purified, and the composition determined (Table 3). The results would be consistent with an oligosaccharide unit containing two residues of galactose, one of $\mathrm{N}$-acetylglucosamine and two of sialic acid linked through $N$-acetylgalactosamine to a hydroxy amino acid. The $N$-acetylgalactosaminitol content suggests a structure with an equivalent weight of 1330 and 748 when desialylated, in good agreement with the experimental mol.wts. of 1400 and 900 for I-3A and desialylated I-3A respectively as determined by gel-permeation chromatography.

The presence of the sialotetrasaccharide:

$$
\mathrm{SA} \alpha 2 \rightarrow 3 \mathrm{Gal} \beta 1 \rightarrow 3(\mathrm{SA} \alpha 2 \rightarrow 6) \mathrm{GalNAc}
$$

as found on the erythrocyte glycoprotein $\alpha$ (Thomas \& Winzler, 1969), cannot be ruled out. The contaminants detected by t.l.c. of Peak I-3A material may correspond to this native sialotetrasaccharide and its desialylated product $\mathrm{Gal} \beta 1 \rightarrow 3 \mathrm{GalNAc}\left(R_{F}\right.$ 0.20 and 0.45 ; Figs. $5 a$ and $5 b$ respectively). Glockner et al. (1978) detected the disaccharide $\mathrm{Gal} \beta 1 \rightarrow 3 \mathrm{GalNAc}$ in the desialylated material released by alkaline $\mathrm{NaBH}_{4}$ treatment of platelet membranes. The specificity of Arachis hypogaea lectin has been studied extensively (Uhlenbruck et al., 1969; Terao et al., 1975; Lotan et al., 1975; 


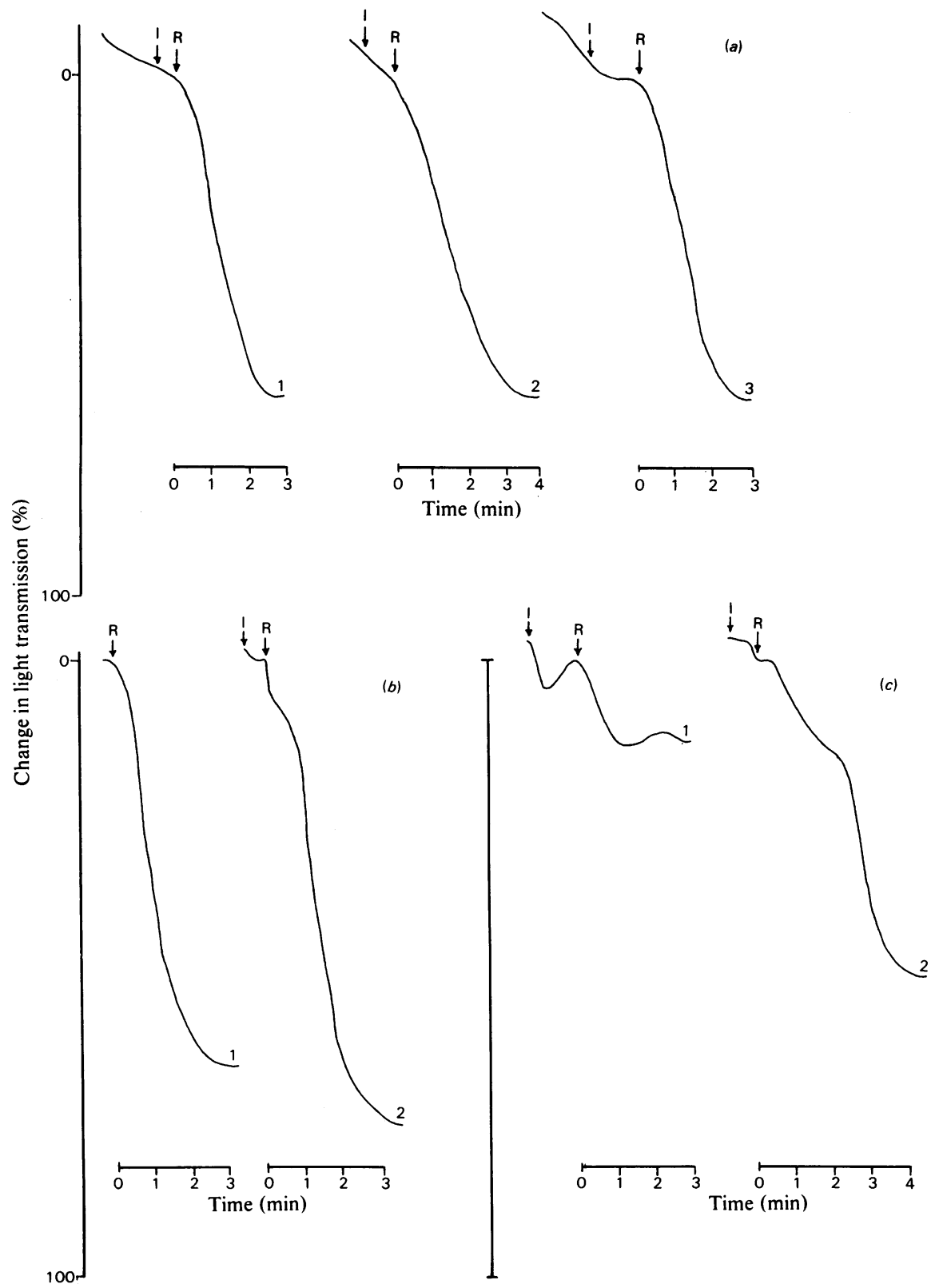

Fig. 7. Inhibition of ristocetin-induced platelet agglutination by glycocalicin, glycopolypeptide and platelet oligosaccharide I-3A

Inhibition of ristocetin-induced agglutination of fresh platelets in autologous plasma was measured as described in the Materials and general methods section. Inhibitor (I), followed by Ristocetin (R), was added to a stirred platelet suspension $\left(2 \times 10^{8} / \mathrm{ml}\right)$ and the change in light transmission at $610 \mathrm{~nm}$ with time recorded. A $1.6 \mathrm{mg}$ portion of ristocetin (R) was added in all cases, except $(c) 1$ and $(c) 2$, where $1.3 \mathrm{mg}$ was added. $(a)$ Effect of glycopolypeptide: $1, \mathrm{I}=0.7 \mathrm{mg}$ of glycopolypeptide; $2, \mathrm{I}=1.4 \mathrm{mg}$ of glycopolypeptide; $3, \mathrm{I}=$ physiological saline $(0.9 \% \mathrm{NaCl}) .(b)$ Effect of oligosaccharide I-3A: 1, no inhibitor added; $2, \mathrm{I}=0.27 \mathrm{mg}$ of oligosaccharide I-3A. (c) Effect of glycocalicin: $1, \mathrm{I}=0.2 \mathrm{mg}$ of glycocalicin; $2, \mathrm{I}=$ physiological saline.

Pereira et al., 1976), and it is widely accepted that it has a preferential reactivity for the disaccharide
Gal $\beta 1 \rightarrow 3$ GalNAc. Since Arachis hypogaea lectin binds exclusively to desialylated GPIb (Judson \& 
Anstee, 1979; Clemetson et al., 1981), the presence of the sialotetrasaccharide described above on GPIb would not be unexpected. The major $O$-linked oligosaccharides of GPIb are, however, sialohexasaccharides containing $N$-acetylglucosamine. This sugar in an $\mathrm{O}$-glycosidically linked oligosaccharide has not previously been described as a constituent of a human blood-cell membrane, although Emerson \& Kornfeld (1976) report such oligosaccharides in bovine erythrocyte membranes. Nevertheless, $\mathrm{N}$ acetylglucosamine is usually found as a constituent of $\mathrm{O}$-glycosidically linked oligosaccharides in mucus glycoproteins such as the blood-group-active glycoproteins of ovarian-cyst fluid, where it may be linked to either the $N$-acetylgalactosamine or the galactose residue of the $\mathrm{Gal} \beta 1 \rightarrow 3 \mathrm{GalNAc}$ core structure (Kabat, 1970; Rovis et al., 1973).

Two possible structures for the sialohexasaccharides of GPIb are: tination of normal fresh platelets. Only glycocalicin showed some inhibition at a concentration of $1.3 \mu \mathrm{M}$ (calculated from mol.wt. 140000). Okumura \& Jamieson $(1976 b)$ reported similar inhibition with glycocalicin in the concentration range $0.25-2 \mu \mathrm{M}$. However, Cooper et al. (1979) reported that their glycocalicin preparation (concentration not specified) did not inhibit bovine Factor VIII-induced platelet agglutination, whereas purified GPIb was an effective inhibitor. It is now generally accepted that glycocalicin is a proteolytic cleavage product of GPIb, probably due to the action of a platelet-derived $\mathrm{Ca}^{2+}$-activated proteinase (Phillips \& Jakábova, 1977; Solum et al., 1980; Clemetson et al., 1981). The probable relationship between the glycopolypeptide, glycocalicin and GPIb is shown in Fig. 8. The evidence from our inhibition experiments and those of others suggests that the numerous $O$-glycosidically linked oligosaccharides

\section{$\mathrm{SA} \alpha 2 \rightarrow 3 \mathrm{Gal} \beta 1 \rightarrow 3,4 \mathrm{GlcNAc} \beta 1 \rightarrow 6(\mathrm{SA \alpha} 2 \rightarrow 3 \mathrm{Gal} \beta 1 \rightarrow 3) \mathrm{GalNAc}$ \\ and \\ $\mathrm{SA} \alpha 2 \rightarrow 3 \mathrm{Gal} \beta 1 \rightarrow 3,4 \mathrm{GlcNAc} \beta 1 \rightarrow 3 \mathrm{Gal} \beta 1 \rightarrow 3(\mathrm{SA} \alpha 2 \rightarrow 6)$ GalNAc}

A number of oligosaccharides have been isolated from human ovarian-cyst glycoproteins (Rovis et al., 1973), two of which (Lewis $R_{L} 0.44$ and Lewis $R_{\text {IMs }} 0.78$ respectively) are closely related to the two possible sialohexasaccharide structures described above. The two sialohexasaccharides and the sialotetrasaccharide all have the $\mathrm{Gal} \beta 1 \rightarrow$ 3GalNAc core structure, and their relative proportions in GPIb would depend on the relative activities of the appropriate transferase enzymes involved in their biosynthesis.

Our data do not give an unequivocal answer to the question of the presence of $N$-linked oligosaccharides in the glycopolypeptide. Both the untreated and alkaline-borohydride-treated glycopolypeptide contained a small amount of asparagine and also mannose, which is usually present in $N$-linked oligosaccharides together with $N$-acetylglucosamine and galactose (Table 2). However, the molar amount of $\mathrm{N}$-acetylglucosamine and galactose does not appear to be sufficient to allow for the presence of a complex-type unit such as that found in the major sialoglycoprotein of the human erythrocyte (Yoshima et al., 1980).

The functional role of GPIb is not clearly defined, but its importance as a receptor in the adhesion of platelets to subendothelial structures and in ristocetin-induced platelet agglutination, both of which require Factor VIII/von Willebrand factor in plasma, has been emphasized (Phillips, 1980). We investigated the ability of I-3A, the major oligosaccharide of glycoprotein $\mathrm{Ib}$, the glycopolypeptide and glycocalicin to inhibit ristocetin-induced agglu- on the glycopolypeptide portion of glycoprotein Ib are not specific receptors for Factor VIII/von Willebrand factor. Nevertheless, the fact that chymotrypsin-treated platelets are not agglutinated by ristocetin (Jenkins et al., 1976) suggests that the presence of the glycopolypeptide is important for maintaining the correct conformation of the Factor VIII/von Willebrand factor receptor at the platelet surface. Other, as yet unidentified, changes resulting from chymotrypsin treatment may, however, be involved.

The function of carbohydrate at cell surfaces is poorly understood. Our results suggest that the carbohydrate of GPIb does not play a specific role in platelet adhesion. However, as described above, GPIb has structural features similar to those of mucus glycoproteins. The main functions of mucus glycoproteins in the gastrointestinal tract, namely lubrication and protection, depend on the formation of a visco-gelatinous covering of the endothelial lining which results from the interaction between the carbohydrate side chains and water molecules (Allen, 1978). The numerous carbohydrate side chains of GPIb might give rise to an analogous covering at the platelet surface. Such covering could present a barrier preventing the contact of macromolecules with the membrane (Edwards, 1978). Since the two primary functions of platelets, adhesion and aggregation, are mediated by macromolecules (Factor VIII/von Willebrand factor and fibrinogen respectively; Phillips, 1980), the existence of such a barrier could have a major role in modulating platelet function. 


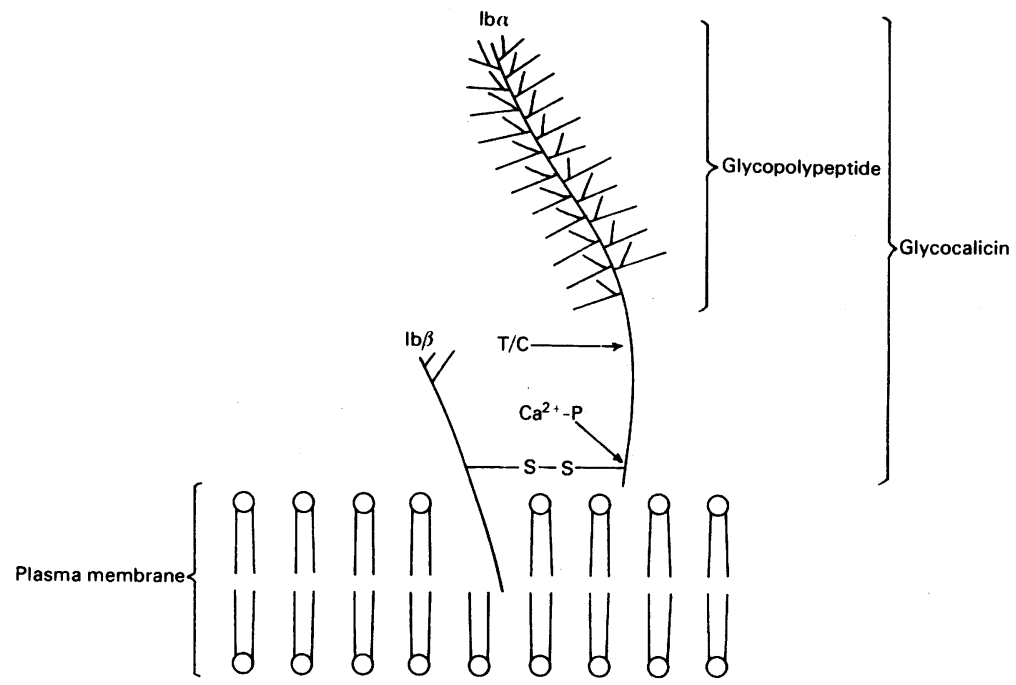

Fig. 8. Possible orientation of GPIb in the platelet plasma membrane (modified from Phillips, 1980)

The presumed sites of action of trypsin (T), $\alpha$-chymotrypsin (C) and the $\mathrm{Ca}^{2+}$-activated proteinase $\left(\mathrm{Ca}^{2+}-\mathrm{P}\right)$ are indicated. $\rightarrow$ indicates the presence of $O$-glycosidically linked oligosaccharides.

We thank Dr. G. Farrar and Dr. R. Harrison, University of Bath, and Dr. M. J. A. Tanner, University of Bristol, for their help and guidance with various aspects of this work, also Mrs. Margaret Clark for typing the manuscript and drawing the Figures.

\section{References}

Allen, A. (1978) Br. Med. Bull. 34, 28-33

Aminoff, D. (1961) Biochem. J. 81, 384-392

Anstee, D. J., Mawby, W. J. \& Tanner, M. J. A. (1979) Biochem.J. 183, 193-203

Barber, A. J. \& Jamieson, G. A. (1970) J. Biol. Chem. 245, 6357-6365

Barber, A. J. \& Jamieson, G. A. (1971) Biochemistry 10, 4711-4717

Clamp, J. R. (1977) Biochem. Soc. Trans. 5, 1693-1695

Clemetson, K. J., Niam, H. Y. \& Lüscher, E. F. (1981) Proc. Natl. Acad. Sci. U.S.A. 78, 2712-2716

Cooper, H. A., Clemetson, K. J. \& Lüscher, E. F. (1979) Proc. Natl. Acad. Sci. U.S.A. 76, 1069-1073

Davey, M. G. \& Lüscher, E. F. (1967) Nature (London) 216, 857-858

Dische, Z. \& Danilchenko, A. (1967) Anal. Biochem. 21, 119-124

Donald, A. S. R. (1973) Biochim. Biophys. Acta 317, 420-436

Edwards, P. A. W. (1978) Br. Med. Bull. 34, 55-56

Emerson, W. A. \& Kornfeld, S. (1976) Biochemistry 15, 1697-1703

Farrar, G. H. \& Harrison, R. (1978) Biochem. J. 171, 549-557

Glockner, W. M., Kaulen, H. D. \& Uhlenbruck, G. (1978) Thromb. Haemostasis 39, 186-192
Goodwin, S. D. \& Watkins, W. M. (1974) Eur. J. Biochem. 47, 371-382

Humbel, R. \& Collart, M. (1975) Clin. Chim. Acta 60, 143-148

Hummel, B. C. W. (1959) Can. J. Biochem. Physiol. 37, 1393-1399

Jenkins, C. S. P., Phillips, D. R., Clemetson, K. J., Meyer, D., Larrieu, M.-J. \& Lüscher, E. F. (1976) J. Clin. Invest. 57, 112-124

Judson, P. A. \& Anstee, D. J. (1979) Protides Biol. Fluids Proc. Colloq. 27, 871-874

Kabat, E. A. (1970) in Blood and Tissue Antigens (Aminoff, D., ed.), pp. 187-198, Academic Press, London and New York

Laemmli, U. K. (1970) Nature (London) 227, 680-682

Lotan, R., Skutelsky, E., Danon, D. \& Sharon, N. (1975) J. Biol. Chem. 250, 8518-8522

Lowry, O. H., Rosebrough, N. A., Farr, A. L. \& Randall, R. J. (1951) J. Biol. Chem. 193, 265-275

Nurden, A. T. \& Caen, J. P. (1978) Br. J. Haematol. 38, $155-160$

Okumura, T. \& Jamieson, G. A. (1976a) J. Biol. Chem. 251, 5944-5949

Okumura, T. \& Jamieson, G. A. (1976b) Thromb. Res. 8, 701-706

Okumura, T., Lombart, C. \& Jamieson, G. A. (1976) J. Biol. Chem. 251, 5950-5955

Pepper, D. S. \& Jamieson, G. A. (1970) Biochemistry 9 , 3706-3713

Pereira, M. W., Kabat, E. A., Lotan, R. \& Sharon, N. (1976) Carbohydr. Res. 51, 107-118

Phillips, D. R. (1980) Prog. Haemostasis Thromb. 5, 81-109

Phillips, D. R. \& Jakábova, M. (1977) J. Biol. Chem. 252, 5602-5605

Vol. 205 
Phillips, D. R. \& Poh Agin, P. (1977) J. Biol. Chem. 252, 2121-2126

Podolsak, B. (1977) Thromb. Haemostasis 37, 396406

Reid, L. \& Clamp, J. R. (1978) Br. Med. Bull. 34, 5-8

Rovis, L., Anderson, B., Kabat, E., Gruezo, F. \& Liao, J. (1973) Biochemistry 12, 5340-5354

Solum, N. O., Hagen, I., Filion-Myklebust, C. \& Stabaek, T. (1980) Biochim. Biophys. Acta 597, 235-246

Svennerholm, L. (1957) Biochim. Biophys. Acta 24, 604-611

Tanner, M. J. A. \& Anstee, D. J. (1976) Biochem. J. 153, 265-270
Tanner, M. J. A., Anstee, D. J. \& Mawby, W. J. (1980) Biochem. J. 187, 493-500

Taylor, M. A. (1981) J. Clin. Pathol. 34, 71-75

Terao, T., Irimura, T. \& Osawa, T. (1975) Hoppe-Seyler's Z. Physiol. Chem. 356, 1685-1692

Thomas, D. B. \& Winzler, R. J. (1969) J. Biol. Chem. 244, 5943-5946

Uhlenbruck, G., Pardoe, G. I. \& Bird, G. W. G. (1969) Z. Immunitatsforsch. 138, 423-433

Yoshima, H., Furthmayr, H. \& Kobata, A. (1980) J. Biol. Chem. 255, 9713-9718

Zacharias, R. J., Zell, T. E., Morrison, J. H. \& Woodcock, J. J. (1969) Anal. Biochem. 30, 148-154 